\title{
Editorial - Launch of the Freshwater Metadata Journal (FMJ)
}

Astrid Schmidt-Kloiber, Robert Vogl, Aaike De Wever \& Koen Martens
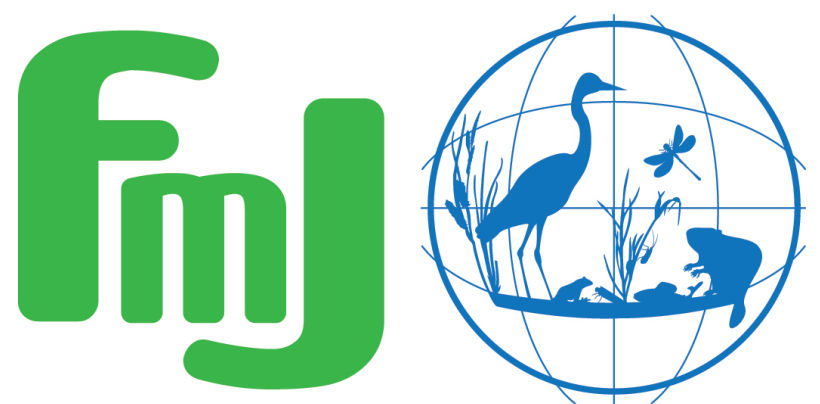

Freshwater Metadata Journal 



\title{
Editorial - Launch of the Freshwater Metadata Journal (FMJ)
}

\author{
Astrid Schmidt-Kloiber ${ }^{1}$, Robert Vogl ${ }^{1}$, Aaike De Wever $^{2}$ \& Koen Martens ${ }^{2}$ \\ ${ }^{1}$ BOKU - University of Natural Resources and Life Sciences, Vienna, Austria; corresponding author: astrid.schmidt-kloiber@boku.ac.at \\ 2 RBINS - Royal Belgian Institute of Natural Sciences, Brussels, Belgium
}

Please cite this paper as follows: Schmidt-Kloiber A., Vogl R., De Wever A. \& Martens K., 2014. Editorial Launch of the Freshwater Metadata Journal (FMJ). Freshwater Metadata Journal 1: 1-4.

http://dx.doi.org/10.15504/fmj.2014.1

Received: 2014-10-07 / Published: 2014-10-07

\section{Background of the BioFresh metadatabase}

During the past four years, the EU funded project "BioFresh" (Biodiversity of Freshwater Ecosystems: Status, Trends, Pressures, and Conservation Priorities; www.freshwaterbiodiversity.eu) built an information platform with access to available datasets on the distribution, status and trends of global freshwater biodiversity, to be used by scientists, ecosystem managers and the interested public. From a data management point of view, the main objectives were to mobilise freshwater biodiversity related datasets, register them in the BioFresh metadatabase on the one hand and to present freshwater biodiversity data (mostly species occurrence data) on the BioFresh data portal on the other hand. Both turned out to be major challenges.

The value of metadata - i.e. the who, why, what, when and where of a given dataset - in ecological sciences is well recognised by now (see for example Fegraus et al. 2005, Michener et al. 1997, Michener 2006, Michener \& Jones 2012) and collecting such data is already getting common in the scientific community. A metadatabase - first initiated by the WISER project (Hering et al. 2012, Schmidt-Kloiber et al. 2012) - was adapted for a more general use within BioFresh and tools to fill in and query the collected information were made available through the BioFresh data portal (data.freshwaterbiodiversity.eu).

\section{Data mobilising challenges in BioFresh}

As already stated above, data mobilisation within BioFresh was not always straightforward. While some of the data holders addressed us with the wish to publish their data through BioFresh, others were reluctant to do so. There may be several reasons for this reluctance (Schmidt-Kloiber et al. 2012):

- time \& financial constraint: the preparation of heterogeneous data and the provision of accurate information and sufficient documentation for the reuse of data requires time and therefore financial resources of the scientists involved; 
- usage constraint: scientists fear that their data might be used for an incorrect purpose or in an incorrect way;

- intellectual property rights constraint: scientists believe that releasing data means abandoning intellectual property rights.

A comprehensive and accurate documentation of a dataset - as made possible through the BioFresh metadatabase - avoids at least the latter two issues and will pave the way to fully open access data.

\section{Rationale of the Freshwater Metadata Journal}

There is evidence that online publication of research data benefits scientists (Costello 2009) and Chavan \& Penev (2011) advertise the "(meta)data paper" as a mechanism to incentivise actual data publishing. Recent efforts to make freshwater data easily available (see Penev et al. 2011 for an overview) include the initiative to mobilise freshwater biodiversity data through requiring them together with journal publications (De Wever et al. 2012) or the creation of a dedicated journal to encourage data publication and mobilise small datasets ("Biodiversity Data Journal"; Smith et al. 2013). With the creation of the Freshwater Metadata Journal (FMJ) we want to support such ventures and bring about a change of perception regarding data publishing within in the freshwater community.

After entering information about a dataset in the BioFresh metadatabase, a fully automated process creates a metadata article in the FMJ, thereby saving the scientists' time (for a pictorial representation of the entire workflow, see Figure 1). After an editorial review process, the article is assigned a digital object identifier (DOI) and is made accessible on the FMJ website (www.freshwaterjournal.eu), thereby making the dataset information citeable and traceable, just like any other standard scientific article. We are convinced that such FMJ articles will make scientists' study efforts more visible to other researchers. The easy publishing process as well as the possibility for citation should serve as incentives for scientists to make information on a dataset, and finally the dataset itself, publicly available, again helping to create more recognition of one's work.

The FMJ has an ISSN registration and publishing is completely in open access and fully free of charge. The editor in chief is Astrid Schmidt-Kloiber (Institute of Hydrobiology \& Ecosystem Management, BOKU University of Natural Resources and Life Sciences, Vienna, Austria), who currently also reviews all articles together with the metadatabase quality control team of BOKU (Anne Hartmann, Ilse Stubauer). An advisory editorial board consists of former participants of the BioFresh project, but will be expanded with new members in the future.

We thus herewith proudly announce the launch of the Freshwater Metadata Journal. Please check out our webpage (www.freshwaterjournal.eu) and do not hesitate to contact us for any further information or if you need assistance whilst submitting your metadata. 


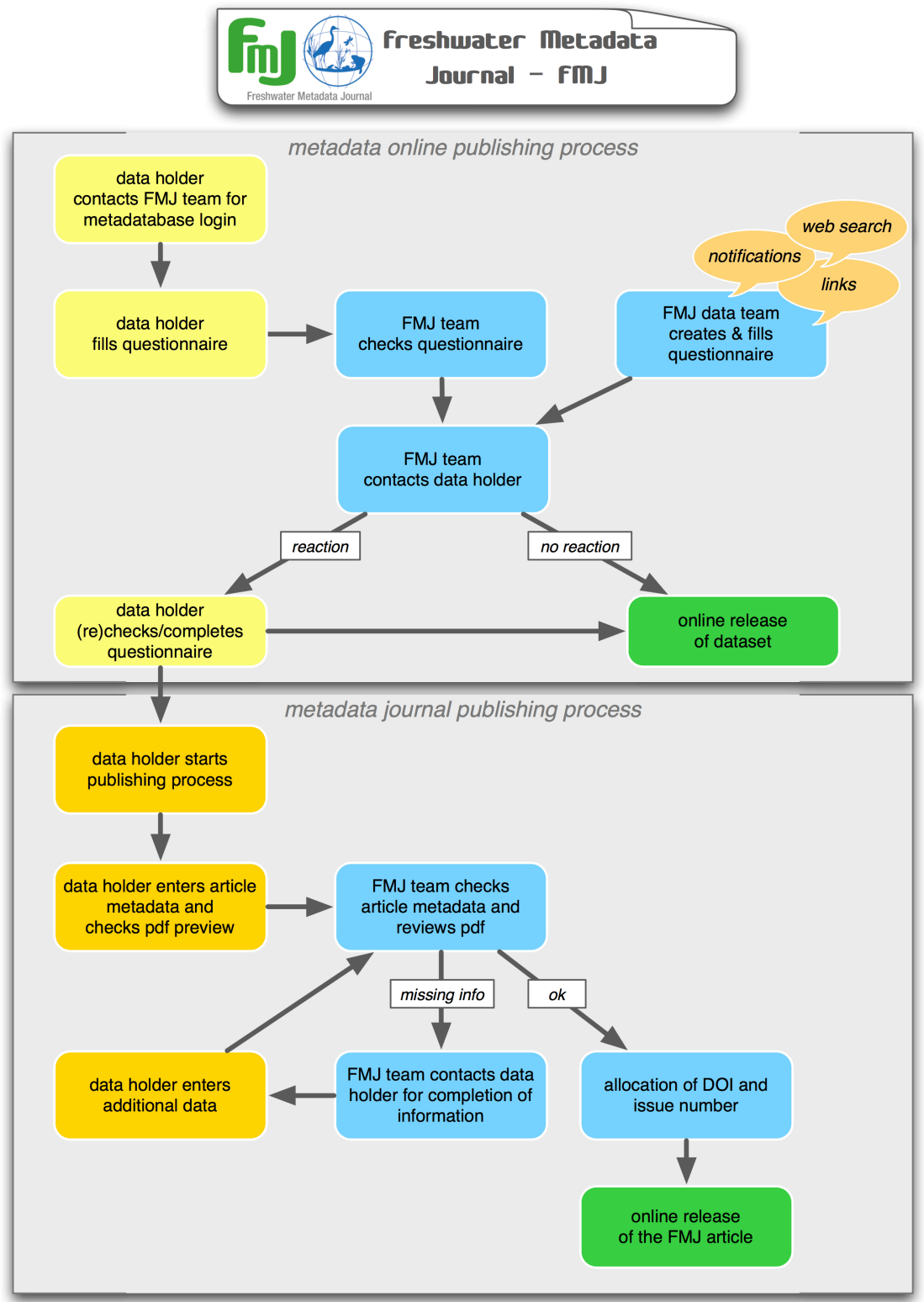

Figure 1: Workflow of publishing metadata in the BioFresh metadatabase (upperpart) and in the Freshwater Metadata Journal (lowerpart).

\section{Acknowledgements}

The initiation of this journal was funded by the BioFresh project (Biodiversity of Freshwater Ecosystems: Status, Trends, Pressures, and Conservation Priorities; EU Framework Programme 7; contract number 226874; www.freshwaterbiodiversity.eu). Final developments were realised within the MARS project (Managing Aquatic ecosystems and water Resources under multiple Stress; EU Framework Programme 7; contract number 603378; www.mars-project.eu).

\section{References}

Chavan, V. \& L. Penev, 2011. The data paper: a mechanism to incentivize data publishing in biodiversity science. BMC Bioinformatics 12 (Suppl 15): S2. http://dx.doi.org/10.1186/1471-2105-12-S15-S2

Costello, M. J., 2009. Motivating online publication of data. BioScience 59(5): 418-427.

http://dx.doi.org/10.1525/bio.2009.59.5.9 
De Wever, A., A. Schmidt-Kloiber, M. O. Gessner \& K. Tockner, 2012. Freshwater journals unite to boost primary biodiversity data publication. BioScience 62(6): 529-530.

http://dx.doi.org/10.1525/bio.2012.62.6.2

Fegraus, E. H., S. Andelman, M. B. Jones \& M. Schildhauer, 2005. Maximizing the value of ecological data with structured metadata: an introduction to Ecological Metadata Language (EML) and principles for metadata creation. Bulletin of the Ecological Society of America 86(3): 158-168.

http://dx.doi.org/10.1890/0012-9623(2005)86\%5B158:MTVOED\%5D2.0.CO;2

Hering, D., A. Borja, L. Carvalho \& C. K. Feld, 2012. Assessment and recovery of European water bodies: key messages from the WISER project. Hydrobiologia 704: 1-9. http://dx.doi.org/10.1007/s10750-012-1438-9

Michener, W. K., J. W. Brunt, J. J. Helly, T. B. Kirchner \& S. G. Stafford, 1997. Nongeospatial metadata for the ecological sciences. Ecological Applications 7(1): 330-342.

http://dx.doi.org/10.1890/1051-0761(1997)007\%5B0330:NMFTES\%5D2.0.CO;2

Michener, W. K., 2006. Meta-information concepts for ecological data management. Ecological Informatics 1(1): 3-7. http://dx.doi.org/10.1016/j.ecoinf.2005.08.004

Michener, W. K. \& M. B. Jones, 2012. Ecoinformatics: supporting ecology as a data-intensive science. Trends in Ecology \& Evolution 27(2): 85-93. http://dx.doi.org/10.1016/j.tree.2011.11.016

Penev, L., D. Mietchen, V. Chavan, G. Hagedorn, D. Remsen, V. Smith \& D. Shotton, 2011. Pensoft Data Publishing Policies and Guidelines for Biodiversity Data. Pensoft Publishers [available on internet at http://www.pensoft.net/I FILES/Pensoft Data Publishing Policies and Guidelines.pdf].

Schmidt-Kloiber, A., S. J. Moe, B. Dudley, J. Strackbein \& R. Vogl, 2012. The WISER metadatabase: the key to more than 100 ecological datasets from European rivers, lakes and coastal waters. Hydrobiologia 704: 2938. http://dx.doi.org/10.1007/s10750-012-1295-6

Smith, V., T. Georgiev, P. Stoev, J. Biserkov, J. Miller, L. Livermore, E. Baker, D. Mietchen, T. Couvreur, G. Mueller, T. Dikow, K. Helgen, J. Frank, D. Agosti, D. Roberts \& L. Penev, 2013. Beyond dead trees: integrating the scientific process in the Biodiversity Data Journal. Biodiversity Data Journal 1: e995. http://dx.doi.org/10.3897/BDJ.1.e995 